\title{
THE USE OF BLOSS CURVE IN THE EXIT LANES OF ROAD INTERSECTIONS
}

\section{DONATO CIAMPA*, SAVERIO OLITA}

School of Engineering, University of Basilicata, Potenza, Italy

Received 23 September 2019; accepted 13 November 2019

\begin{abstract}
The paper proposes the use of the Bloss curve (also known as biparametric or bi-hyperclothoid) as a braking curve in the exit lanes of road intersections. The main international standards continue using the clothoid as the principal transitional geometric element, even though the limits of its use in driving regimes with non-uniform speeds are known. The proposal to use the Bloss curve is aimed at overcoming these limitations and opening a debate on the possible need to codify, even in the international standards, the use of more suitable alternative braking curves. In this context, a kinematic study was conducted by comparing the main parameters of the motion (lateral jerk, lateral acceleration, steering speed) between the Bloss curve and more traditional curves, such as clothoid and Generalized Cornu Spirals (GCS). Nine case studies were conducted, each case was characterized considering the type of transition curve used (clothoid, GCS and Bloss curve) and radius $R$ of the exit curve $(R=60 \mathrm{~m}, 80 \mathrm{~m}, 100 \mathrm{~m})$. The numerical values assumed by the kinematic variables along the transition curves were "locally" calculated, i.e. "pointby-point", to take into account the non-uniform motion regime. The results obtained, limited to the cases studied, show that the Bloss curve better meets the kinematic conditions of the vehicle motion in non-uniform driving regimes. Therefore, the Bloss curve can be considered as a braking curve in the design of road intersections and be a candidate for further investigation to assess any
\end{abstract}

* Corresponding author. E-mail: donato.ciampa@unibas.it

Donato CIAMPA (ORCID iD 0000-0002-2575-0049)

Saverio OLITA (ORCID iD 0000-0001-9495-091X)

Copyright (C) 2020 The Author(s). Published by RTU Press

This is an Open Access article distributed under the terms of the Creative Commons Attribution License (http://creativecommons.org/licenses/by/4.0/), which permits unrestricted use,

distribution, and reproduction in any medium, provided the original author and source are credited. 
additional benefits in terms of comfort, driving safety and visual perception of the geometric element.

Keywords: Bloss curve, braking curve, Generalized Cornu Spirals (GCS), lateral acceleration, lateral jerk, rolling speed, steering speed.

\section{Introduction}

Transition curves are generally divided into two groups (La Camera, 1992): curves that can be traveled at constant speed and curves corresponding to vehicular trajectories with variable speed. The curves belonging to the first group can be further categorized in two subfamilies depending on two geometric parameters, such as the curvilinear abscissa $s$ and curvature $\rho$. The clothoid $(s / \rho=$ constant) is the main curve of the first subfamily. In modern road design, the clothoid is no longer regarded as the ideal line, but as a special case $(n=1)$ of the largest family of two-parameter spiral curves, $s^{n} / \rho=$ constant, where $n$ is the shape parameter.

The second group includes curves suitable for use at significantly variable speeds, their use is essential in certain road sections, such as exit lanes of intersections where they also perform speed control function.

All these curves have as theoretical reference the fundamental studies that Blaschke $(1956,1958,1959)$ and Heller \& Blaschke (1961) conducted on the travel dynamics of exit lanes that allowed defining the ideal line covered by a vehicle in deceleration motion. The difficulties in expressing the intrinsic equation of this line in Cartesian/parametric form have promoted the study of curves with similar characteristics and simpler mathematical expressions. The Generalized Cornu Spiral (GCS) belongs to this family; with the appropriate choice of its shape factor $n$, it better explains the dynamic and design conditions (La Camera, 1992).

In this paper, the authors, after describing the main geometric and kinematic characteristics of clothoids and GCS, have examined another transition curve called the Bloss curve (Bloss, 1936) and have evaluated its suitability to be used in the exit lanes of road intersections.

It should be noted that over the years, the Bloss curve has been studied by many authors who have investigated its mathematical and geometric aspects (Ciobanu, 2015; Kobriń, 2017; Wladyslaw, 2014). Studies on the Bloss curve have shown its affinity with the family of GCS so that it is also known as biparametric or bi-hyperclothoid curve (Agostinacchio, 1983).

However, there are relatively few studies on the use of the Bloss curve as a braking curve and these studies have been mainly conducted in the 
railway sector (Kufver, 1997; Wladyslaw, 2014). Therefore, at present, the use of this curve in the exit lanes of road intersections is quite innovative.

\section{Transition curves in road design}

The main geometrical and kinematic characteristics of the transition curves considered in this study (clothoid, GCS and Bloss curve) are listed below.

\subsection{Clothoid}

The clothoid is used as a transition curve between two elements with constant curvature. If we indicate the scale factor with $A$, the curve radius with $r$ and the curvilinear abscissa with $s$, its intrinsic equation results in:

$$
r \times s=A^{2} .
$$

It can be seen that the clothoid is characterized by a linear trend of curvature $1 / r$ along the curvilinear abscissa. Through Eq. (1) and exploiting the existing link between the final deviation angle $\tau$, curvature $1 / r$ and curvilinear abscissa $s(\mathrm{~d} \tau=\mathrm{d} s / r)$ it is possible to identify, in the closed form, a series of relations that interconnect the variables described previously, that are:

$$
\tau=\frac{s^{2}}{2 A^{2}}=\frac{s}{2 r}=\frac{A^{2}}{2 r^{2}} .
$$

The Cartesian equation of the clothoid cannot be expressed in the closed form, as can be observed from expression (3) given below (Agostinacchio et al., 2010; La Camera, 1992):

$$
\left\{\begin{array}{l}
x=A \sqrt{2 \tau} \sum_{i=1}^{\infty}(-1)^{i+1} \frac{\tau^{(2 i-2)}}{(4 i-3)(2 i-2) !} \\
y=A \sqrt{2 \tau} \sum_{i=1}^{\infty}(-1)^{i+1} \frac{\tau^{(2 i-1)}}{(4 i-1)(2 i-1) !} .
\end{array}\right.
$$

To ensure that the clothoid can be used in road design, the minimum value of the scale factor $\left(A_{\min }\right)$ must be greater than the larger of the minimum values obtained by applying various criteria, such as the dynamic criterion (or lateral jerk limitation criterion), the constructive criterion (based on the $\Delta S_{\max }$ value - maximum superelevation rate) and the optical criterion. Compliance with the above-mentioned criteria ensures optimum conditions of limiting the rate of change in lateral 
Table 1. Limitations to the clothoid scale parameter $A$

\begin{tabular}{cccc}
\hline Criterion & $\boldsymbol{A}_{\min }$ & $\boldsymbol{A}_{\max }$ & Notes \\
\hline Dynamic & $0.021 \mathrm{~V}^{2}$ & & $V$ - maximum velocity, $\mathrm{km} / \mathrm{h}$ \\
Constructive & $\sqrt{\frac{P_{t} b}{\Delta S_{\max }}}$ & & $\Delta S_{\max }=\frac{18 b}{100 \mathrm{~V}}$ \\
Optical & $\frac{R}{3}$ & & Recommended limit \\
\hline
\end{tabular}

acceleration $c$ and rolling speed of the roadway $\dot{u}$. The maximum value of the scale parameter $A_{\max }$ must not exceed the radius of the circular curve $R$ at the end point of the clothoid. The analytical expressions of these criteria are summarized in Table 1 (Agostinacchio et al., 2010; MIT, 2001).

The expression of the constructive criterion (Table 1) refers to the general case in which the clothoid connects a straight line to a circular curve of radius $R$ and the axis of rotation coincides with the axis lane of the roadway. In the case of single slope straight line, $P_{t}=q_{f}-q_{i}$ is found, where $q_{f}$ and $q_{i}$ respectively identify the roadway slope at the end and the beginning of the transition curve. Indicator $b$ defines the distance (in meters) between the axis of rotation and the edge of the carriageway in the initial and final clothoid points.

The $A$ values can also be calculated with other parameters, such as the steering speed $\dot{\vartheta}(\mathrm{rad} / \mathrm{s})$, where $\vartheta$ is the steering angle in radians, travel speed $v(\mathrm{~m} / \mathrm{s})$ and vehicle wheelbase $p(\mathrm{~m})$, applying the following expression (Agostinacchio et al., 2010):

$$
A=\sqrt{\frac{p v}{\dot{\vartheta}}} .
$$

As a general rule, to evaluate the effectiveness of clothoid use in road track, it is necessary to study the trends of at least three kinematic quantities, the transversal acceleration $a_{t}$, lateral jerk $c$ (variation of transversal acceleration in the unit of time) and steering speed $\dot{\vartheta}$, whose analytical expressions (for $n=1$ ) are (Giannini et al., 1993):

$$
\begin{gathered}
a_{t}=\frac{v^{2}}{r}=\frac{v^{2}}{A^{2}} s ; \\
c=\frac{\mathrm{d} a_{t}}{\mathrm{~d} t}=\frac{v^{3}}{A^{2}} ; \\
\dot{\vartheta}=\frac{p v}{A^{2}}=\frac{p}{v^{2}} .
\end{gathered}
$$


A further kinematic parameter to be considered is $\dot{u}$, rolling speed of the roadway. Its value (expressed in $\mathrm{rad} / \mathrm{s}$ ) is obtained by applying the following expression (8):

$$
\dot{u}=\frac{\vartheta_{f}-\vartheta_{x}}{t},
$$

where $\vartheta_{f}$ - roadway rotation angle (single slope) at the end of the transition curve, rad; $\vartheta_{x}$ - roadway rotation angle (single slope) at the beginning of the transition curve, rad; $t$ - travel time of the transition curve, $\mathrm{s}$.

As it is generally known, the clothoid is only fully effective in uniform driving regimes, given that under such conditions, the jerk and steering speed remain constant (Eqs. (6) and (7)) and the lateral acceleration varies with a linear trend (Eq. (5)).

\subsection{Generalized Cornu Spirals (GCS) and braking curves}

Generalized Cornu Spirals are variable radius curves defined by the following intrinsic equation (Nemesdy, 1984):

$$
r \times S^{n}=A^{n+1},
$$

where the parameter $n \neq 1$ is called the shape factor. This equation is related to the clothoid case when $n$ takes on a unitary value (Eq. (1)). For $n>1$ and $n<1$, GCS curves are called hyperclothoid and hypoclothoid, respectively.

Similar to the clothoid (Eq. (3)), the Cartesian equation cannot be expressed in the closed form for the GCS either (La Camera 1992):

$$
\left\{\begin{array}{l}
x=A \sqrt[n+1]{(n+1) \tau}\left[\sum_{i=1}^{\infty}(-1)^{i+1} \frac{\tau^{(2 i-2)}}{(2 i-2) ! p_{i}}\right] \\
y=A \cdot \sqrt[n+1]{(n+1) \tau}\left[\sum_{i=1}^{\infty}(-1)^{i+1} \frac{\tau^{(2 i-1)}}{(2 i-1) ! q_{i}}\right]
\end{array}\right.
$$

where

$p_{i}=(2 i-2)(n+1)+1=2 i n+2 i-2 n-1$;

$q_{i}=(2 i-1)(n+1)+1=2 i n+2 i-n$;

$q_{i}=p_{i}+n+1$.

From Eq. (10) it is possible to obtain all geometric characteristics of GCS. The same considerations on the $A$ scale parameter developed for the clothoid (Table 1) are valid for GCS. These limitations are summarized in Table 2 for $n \neq 1$ (La Camera, 1992).

The trends in lateral acceleration $a_{t}$, lateral jerk $c$ and steering speed $\dot{\vartheta}$ are described by the following analytical expressions, which are also valid for $n=1$ (Giannini et al., 1993): 


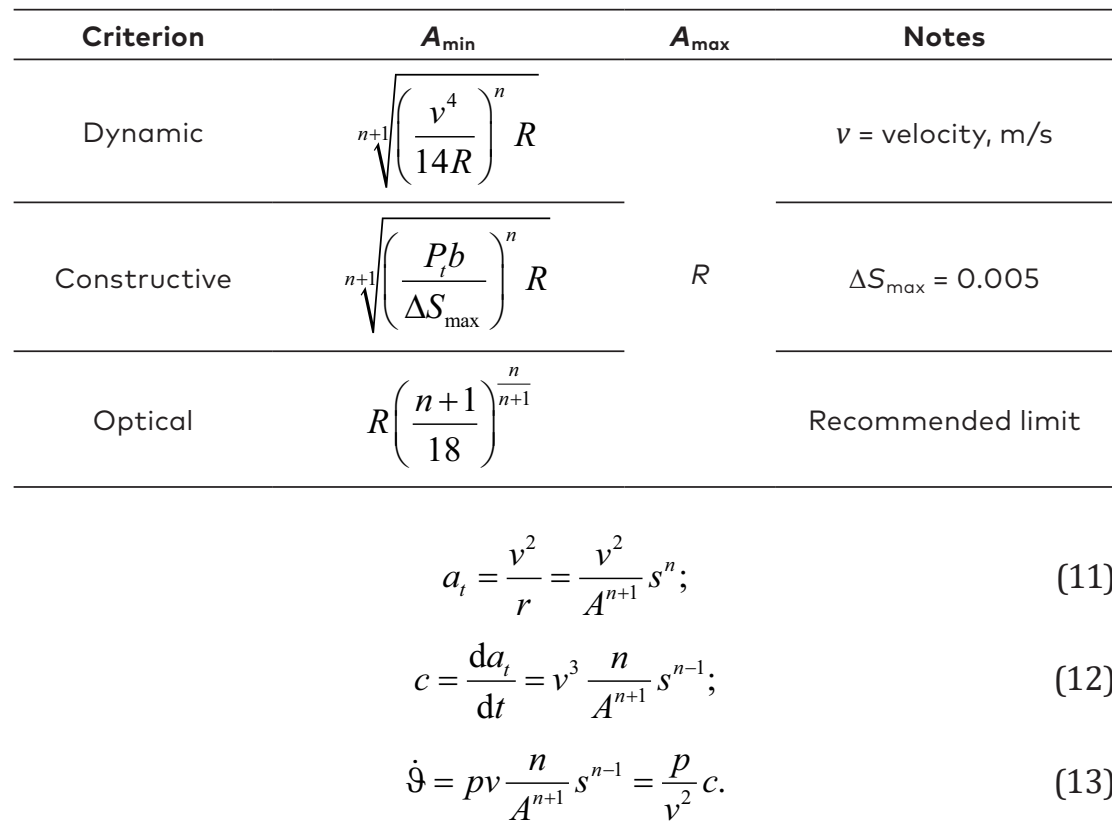

For the rolling speed $\dot{u}$ nothing changes with respect to the clothoid (Eq. (8)).

The braking curves derive from Blaschke and Heller's research into the dynamics of vehicles travelling on the exit ramps of junctions. This research allowed identifying a behavior pattern characterized by constant jerk and longitudinal deceleration over time. The limit of this behavioral model is that it cannot establish the link between the curvature and curvilinear abscissa. The first researcher who proposed to use the hyperclothoid instead of the theoretical braking curve was Lorenz (1971) who suggested the following procedure (La Camera, 1992): the two curves (hyperclothoid and theoretical braking curve) must be equal in terms of initial and final radius values and length, then the corresponding lateral accelerations are calculated point-by-point and the one that minimizes their difference is chosen from the infinite possible solutions.

The shape factor $n$ that guarantees this result is called optimal $n$ $\left(n_{\text {opt }}\right)$. In literature, there are tables that allow identifying its value as a function of variables $N=V_{i} / V_{f}$ and $K=R_{i} / R_{f}$ where $V_{i}, V_{f}, R_{i}$ and $R_{f}$ represent the speeds and the radii of curvature at the beginning and at the end of the transition curve, respectively. These tables (for example, Table 3) allow calculating both the maximum relative variation of lateral acceleration between the design hyperclothoid and the corresponding ideal braking curve (La Camera, 1992). 
Table 3. Optimum $n$-values when parameters $N$ and $K$ change

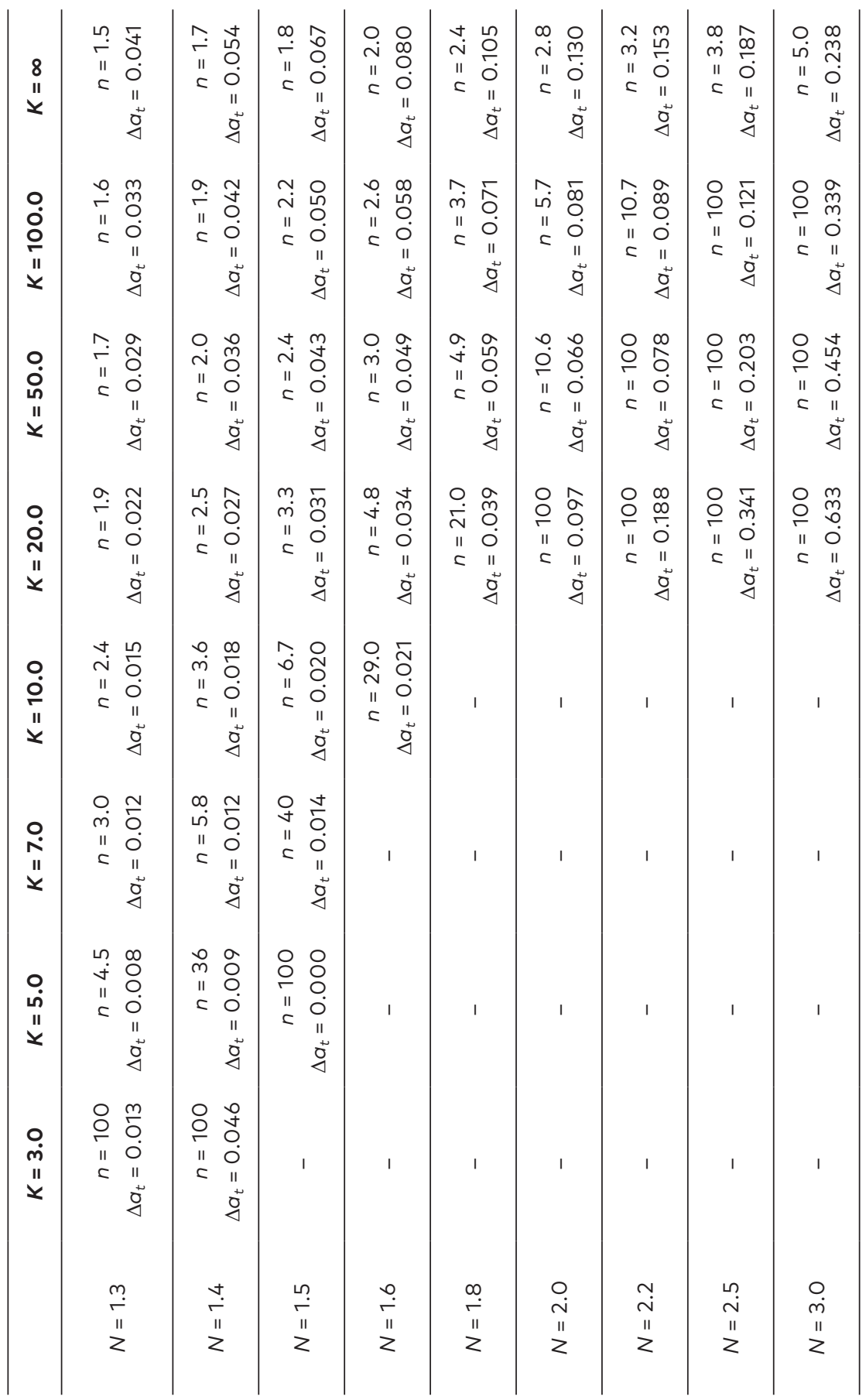


The Bloss curve is a transition curve that reduces the negative effects of geometric discontinuities at the start and end points of the transition curve. The analytical expression of the generic transition curve of length $L$ inserted between a straight line and a circular curve of radius $R$ derives from the equation of a simple 3rd degree polynomial curve (Wladyslaw, 2015), on which four boundary conditions are imposed (Kobryń, 2017): zero curvature and horizontal tangent at the starting point, passing through the midpoint of coordinates $(L / 2 ; 0.5 R)$ and passing through the end point of coordinates $(L ; 1 / R)$. Called $1 / r$, representing the curvature in correspondence with the generic curvilinear abscissa $s$, we obtain the Bloss curve equation in implicit form (Bloss, 1936; Taşçi \& Kuloğ, 2011):

$$
\frac{1}{r}=\frac{s^{2}}{R L^{2}}\left(3-\frac{2 s}{L}\right) .
$$

In Eq. (14), the condition of horizontal tangent at the end point is also met. Some authors (Agostinacchio, 1983) have highlighted that Eq. (14) in the implicit form has an affinity with the equation of the GCS (Eq. (9)). In fact, if it is provided that the curvature $1 / r$ is equal to the difference of two generic curvatures $1 / r_{1}$ and $1 / r_{2}$ :

$$
\begin{aligned}
& \frac{1}{r_{1}}=\frac{s^{2}}{A_{1}^{3}}=\frac{s^{2}}{\left(\frac{R L^{2}}{3}\right)} ; \\
& \frac{1}{r_{2}}=\frac{s^{3}}{A_{2}^{4}}=\frac{s^{3}}{\left(\frac{R L^{3}}{2}\right)},
\end{aligned}
$$

we get just expression (14):

$$
\frac{1}{r}=\frac{1}{r_{1}}-\frac{1}{r_{2}}=\frac{s^{2}}{A_{1}^{3}}-\frac{s^{3}}{A_{2}^{4}}=\frac{s^{2}}{R L^{2}}\left(3-\frac{2 s}{L}\right) .
$$

Eq. (17) allows attributing the name of biparametric (or bi-hyperclothoid) also to the Bloss curve (Agostinacchio, 1983) considering that its intrinsic equation can be obtained from the difference of equations of two GCS with shape factors $n_{1}$ and $n_{2}$ greater than the unit ( $n_{1}=2$ and $n_{2}=3$ ) and with scale factors $A_{1}$ and $A_{2}$ respectively equal to:

$$
A_{1}=\left(\frac{R L^{2}}{3}\right)^{\frac{1}{3}} \text { and } A_{2}=\left(\frac{R L^{3}}{2}\right)^{\frac{1}{4}} .
$$




\begin{tabular}{c|l}
\hline \multicolumn{1}{c|}{ Cartesian equation } & \multicolumn{1}{c}{ Notes } \\
\hline$x=\sum_{i=0}^{n} \frac{(-1)^{i}}{(2 i) !} \sum_{j=0}^{2 i} \frac{(-1)^{j}}{6 i+j+1} \cdot \frac{(2 i) !}{j !(2 i-j) !} \cdot \frac{s^{6 i+j+1}}{\left(3 A_{1}^{3}\right)^{2 i-j}\left(4 A_{2}^{4}\right)^{j}}$ & $\frac{(-1)^{i}}{(2 i) !}=1$ for $i=0$ \\
\cline { 2 - 3 } & $\frac{(2 i) !}{j !(2 i-j) !}=1$ for $j=0$ or $j=2 i$ \\
\hline$y=\sum_{i=0}^{n} \frac{(-1)^{i}}{(2 i+1) !} \sum_{j=0}^{2 i} \frac{(-1)^{j}}{6 i+j+4} \cdot \frac{(2 i+1) !}{j !(2 i+1-j) !} \cdot \frac{s^{6 i+j+4}}{\left(3 A_{1}^{3}\right)^{2 i+1-j}\left(4 A_{2}^{4}\right)^{j}}$ & $\frac{(2 i+1) !}{j !(2 i+1-j) !}=1$ for $j=0$ or $j=2 i+1$ \\
\hline
\end{tabular}

The Cartesian equation of the Bloss curve is shown in Table 4.

If we assume that speed $v$ is constant, then lateral jerk $c$ is written as (Agostinacchio, 1983):

$$
c=\frac{\mathrm{d} a_{t}}{\mathrm{~d} t}=v^{3} \frac{6 s}{R L^{2}}\left(1-\frac{s}{L}\right) .
$$

It is observed that in order to take into account the real conditions of the motion, which is uniformly varied, in the kinematic tests that will be conducted in this study the speed will be "locally" evaluated, i.e. point by point along the transition curves.

Rewriting Eq. (19) according to scale factors (Eq. (18)), we obtain:

$$
c=\frac{\mathrm{d} a_{t}}{\mathrm{~d} t}=v^{3} s\left(\frac{2}{A_{1}^{3}}-\frac{3 s}{A_{2}^{4}}\right) .
$$

Multiplying both members of Eq. (14) by $v^{2}$ we obtain the lateral acceleration expression, that is:

$$
a_{t}=\frac{v^{2}}{r}=\frac{v^{2} s^{2}}{R L^{2}}\left(3-\frac{2 s}{L}\right) .
$$

By appropriately processing expressions (18), it is possible to link two scale factors:

$$
A_{1}=\left(\frac{A_{2}^{4}}{1.5 L}\right)^{\frac{1}{3}} \text { and } A_{2}=\left(1.5 L A_{1}^{3}\right)^{\frac{1}{4}}
$$

The last kinematic parameter to be evaluated is steering speed $\dot{\vartheta}$. Given that $\dot{\vartheta}$ can be expressed in the following form (Giannini et al., 1993):

$$
\dot{\vartheta}=\frac{\mathrm{d} \vartheta}{\mathrm{d} t}=p v \frac{\mathrm{d}\left(\frac{1}{r}\right)}{\mathrm{d} s}
$$


and that from Eq. (14) results (Agostinacchio, 1983):

$$
\frac{\mathrm{d}\left(\frac{1}{r}\right)}{\mathrm{d} s}=\frac{6 s}{R L^{2}}\left(1-\frac{s}{L}\right),
$$

the comparison between Eqs. (23) and (24), and taking into account Eq. (19), results in:

$$
\dot{\vartheta}=p v \frac{6 s}{R L^{2}}\left(1-\frac{s}{L}\right)=\frac{p}{v^{2}} \cdot c .
$$

For the rolling speed $\dot{u}$, the same considerations formulated for the clothoid (Eq. (8)) and the GCS are true.

\section{Exit lanes}

The exit lane is a specialized geometric element that allows vehicle deceleration in the right exit maneuvers. Their width depends on the type of intersection, the type of road (MIT, 2001) and the area context (urban or rural). From a geometric point of view, these lanes are, in general, constituted by the succession of two elementary sections: a taper section of $L_{m, u}$ length, where the vehicle makes the transverse displacement that allows it to leave the lane, and a deceleration section of $L_{d, u}$ length that is determined by a kinematic criterion. In the deceleration section of $L_{d, u}$ length, the vehicle decelerates from the initial speed $v_{1}$ to speed $v_{2}$ appropriate for entering the exit curve. At grade intersections, the length of the taper is $30 \mathrm{~m}$ in the rural area and $20 \mathrm{~m}$ in the urban area (MIT, 2006).

The deceleration value assumed in the exit lane design is equal to $a=2.0 \mathrm{~m} / \mathrm{s}^{2}$ (except for urban and rural highways, where $a=3.0 \mathrm{~m} / \mathrm{s}^{2}$ ). In general:

$$
L_{d, u}=\frac{v_{1}^{2}-v_{2}^{2}}{2 a} .
$$

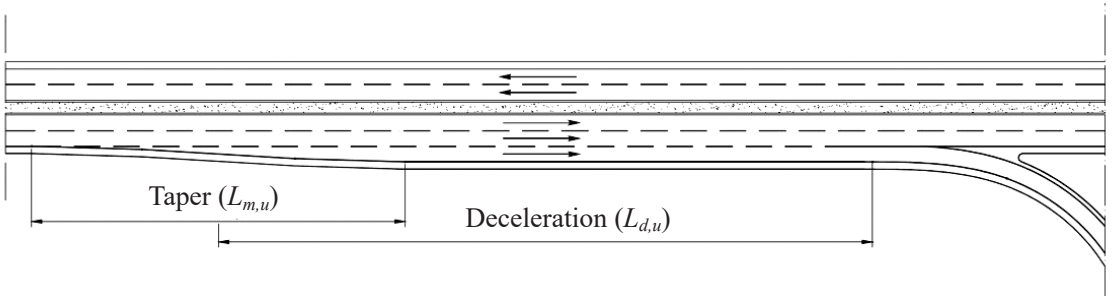

Figure 1. Exit lane (parallel type) 


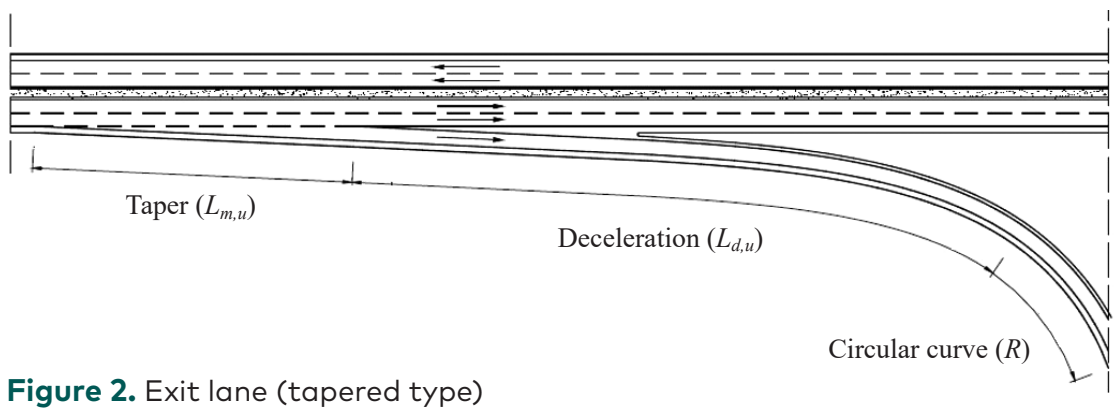

Figure 2. Exit lane (tapered type)

The deceleration section may be parallel to the main axis of the road (Figure 1) or tapered if coincides entirely with the element with variable curvature (Figure 2).

\section{Case studies}

The examined case studies refer to an at-grade intersection exit lane (parallel type) in the rural area (MIT, 2001). Three cases were analyzed considering the transition curve adopted (clothoid, GCS, Bloss curve). These cases were then further subdivided into three sub-cases (for a total of 9 study configurations) according to the value adopted for the planimetric radius of the circular exit curve $(R=60 \mathrm{~m}, 80 \mathrm{~m}, 100 \mathrm{~m})$. Among the various types of GCS it was decided to use the hyperclothoids $(n>1)$ as they are better suited to be used as braking curves in non-uniform driving regimes (La Camera, 1992). To facilitate comparison between various configurations, the different transition curves must have the same length.

The procedure adopted consisted of the following steps:

1) case studies 1-2-3: geometric design of the first three exit lanes (calculation of $L_{m, u}$, calculation of $L_{d, u}$ and design of the hyperclothoids) varying radius $R=60 \mathrm{~m}, 80 \mathrm{~m}, 100 \mathrm{~m}$;

2) case studies 4-5-6: design of further three exit lanes obtained by replacing each hyperclothoids with a clothoid of the same length;

3) case studies 7-8-9: design of three exit lanes obtained by replacing each hyperclothoids with a Bloss curve of equal length.

The nine configurations studied have been designed assuming the real hypothesis of uniformly varied motion, with constant deceleration. A deceleration value of $1.4 \mathrm{~m} / \mathrm{s}^{2}$ was imposed so that this value remained constant both in the deceleration section $L_{d, u}$, and in the subsequent transition curve. This was done is in order to avoid the presence of geometric sections characterized by significantly different motion conditions. 
As already noted (Section 2), the standards require a maximum longitudinal deceleration of $2.0 \mathrm{~m} / \mathrm{s}^{2}$ and this value is generally considered as the limit not to be exceeded to ensure optimal driving comfort (Wu, Liu, \& Pan, 2009). Actually, the deceleration along $L_{d, u}$ is not constant: it is very small in the initial deceleration phase $\left(1.0-1.5 \mathrm{~m} / \mathrm{s}^{2}\right)$ and higher in the braking phase (1.5-3.5 m/s ${ }^{2}$ ) (Zhou, J., Fang, \& Zhou, R.-G., 2013). The average variation (equal to about $1.9 \mathrm{~m} / \mathrm{s}^{2}$ ) coincides, in fact, with the maximum deceleration mentioned above. The value of $1.4 \mathrm{~m} / \mathrm{s}^{2}$ adopted in this study (equal to $70 \%$ of the maximum) is therefore compatible with a safe and comfortable driving regime.

\subsection{Case studies 1-2-3: hyperclothoid}

The deceleration section consists partly of the straight line and partly of the hyperclothoid. However, a rate of $L_{m, u}$ (around 50\%) is used in the deceleration phase of the vehicle (Figure 3). For the geometric design of the hyperclothoid, both the scale parameter $A$ and the form factor $n$ must be calculated. The following expression (27) can be used to calculate the scale factor. It is obtained by manipulating and comparing expression (9) applied at the end point of the hyperclothoid and by expression (26) written for $v_{1}=v_{x}$ and $v_{2}=v_{f}$ :

$$
A=\left\{R\left[\frac{v_{f}^{2}\left(N^{2}-1\right)}{2 a}\right]^{n}\right\}^{\frac{1}{n+1}},
$$

where $R$ - radius of the exit curve $(R=60 \mathrm{~m}, 80 \mathrm{~m}, 100 \mathrm{~m}) ; v_{f}$ - exit curve design speed for $R=60 \mathrm{~m}, 80 \mathrm{~m}, 100 \mathrm{~m}$, i.e. the speed at the end point of the hyperclothoid $\left(v_{f}=8.33 \mathrm{~m} / \mathrm{s}, 9.72 \mathrm{~m} / \mathrm{s}, 11.11 \mathrm{~m} / \mathrm{s}\right.$ corresponding to $\left.V_{f}=30 \mathrm{~km} / \mathrm{h}, 35 \mathrm{~km} / \mathrm{h}, 40 \mathrm{~km} / \mathrm{h}\right) ; v_{x}$ - speed at the starting point of the hyperclothoid, $\mathrm{m} / \mathrm{s} ; N=v_{x} / v_{f} ; a-$ imposed deceleration, equal to $1.4 \mathrm{~m} / \mathrm{s}^{2}$.

It should be noted that for the same considerations developed on the maximum longitudinal deceleration (Section 3) at $v_{f}$ speed, the values on average equal to $70 \%$ of the maximum values laid down in the standards have been attributed (MIT, 2001).

In practice, the values of Table 3 for $N=1.3,1.4,1.5, \ldots, 3.0$ and for $K=\infty$ have been attributed to the parameter $N=V_{x} / V_{f}$ and the corresponding optimal shape factors $\left(n_{\text {opt }}\right)$ have been associated with each of them. Eq. (27) was applied for each pair $\left(N, n=n_{\text {opt }}\right)$ and the corresponding scale factor $A$ was calculated. Subsequently, for each pair $\left(A, n_{\text {opt }}\right)$, Eq. (9) was applied at the final point and the $L_{h y}$ length of the hyperclothoids was calculated in the various examined cases $\left(r=R=60 \mathrm{~m}, 80 \mathrm{~m}, 100 \mathrm{~m}, s=L_{h y}\right)$. Finally, the $v_{x}$ velocities at the starting point of the designed hyperclothoids have been calculated for $v_{2}=v_{f}, v_{1}=v_{x}, L_{d, u}=L_{h y}$ and $a=1.4 \mathrm{~m} / \mathrm{s}^{2}$ (Eq. (26)). 
Table 5. Design hyperclothoids: scale factor $A$ and shape factor $n$

\begin{tabular}{ccccc}
\hline CASE STUDY & $\boldsymbol{R}, \mathbf{m}$ & $\boldsymbol{N}$ & $\boldsymbol{A}, \mathbf{m}$ & $\boldsymbol{n}=\boldsymbol{n}_{\text {opt }}$ \\
\hline 1 & 60 & 1.6 & 44.76 & 2.0 \\
\hline 2 & 80 & 1.6 & 60.52 & 2.0 \\
\hline 3 & 100 & 1.5 & 68.17 & 1.8 \\
\hline
\end{tabular}

The lengths of the deceleration section reduced by the hyperclothoids length $\left(L_{d}=L_{d, u}-L_{h y}\right)$ for $R=60 \mathrm{~m}, 80 \mathrm{~m}, 100 \mathrm{~m}$ are obtained from Eq. (26) after placing $v_{2}=v_{x}, v_{1}=v_{i}, L_{d, u}=L_{d}$ and $a=1.4 \mathrm{~m} / \mathrm{s}^{2}$ (Figure 3). It should be noted that the value of $v_{i}$ was assumed to be $25 \mathrm{~m} / \mathrm{s}(90 \mathrm{~km} / \mathrm{h})$, corresponding to $90 \%$ of the design speed of the main road.

By hypothesis the deceleration is constant $\left(a=1.4 \mathrm{~m} / \mathrm{s}^{2}\right)$ along the entire exit lane (straight and transition curve).

Among all designed hyperclothoids, those characterized by pairs $(A$, $n_{\text {opt }}$ ) able to satisfy the limitations required on the scale parameter have been accepted (Table 2).

Some considerations are necessary. The dynamic criterion has been applied considering the maximum speed $\left(v=v_{x}\right)$ and using the corresponding radius of curvature $R=60 \mathrm{~m}, 80 \mathrm{~m}, 100 \mathrm{~m}$. It was not necessary to carry out the local verification because in all the cases it is $n>1$ and, therefore, the imposed condition is the most precautionary. The constructive criterion was applied by imposing $b=3.50 \mathrm{~m}$ (Tables 1 and 2). In fact, the width of the exit lane $(3.50 \mathrm{~m})$ coincides with the traffic lane width of the main road and then the rotation of the roadway along the transition curve takes place around the inner edge (MIT, 2001, 2006).

The results obtained are shown in Table 5 .

The summary of the geometric and kinematic parameters related to the examined case studies (1-2-3) is given in Table 8.

\subsection{Case studies 4-5-6: clothoid}

The scale factor $A$ is obtained by Eq. (1) for $r=R=60 \mathrm{~m}, 80 \mathrm{~m}, 100 \mathrm{~m}$, $s=L_{\text {clot }}$.

In each case, the length of the clothoid $\left(L_{c l o t}\right)$ is attributed to the value of the corresponding length of the hyperclothoid calculated in Section 3.1 (Table 8 - Case studies 1-2-3). It is easy to demonstrate that all designed clothoids meet the limitations required on the $A$ scale factor (Table 1) and that the latter is always lower than the recommended $A$ maximum value, equal to radius $R$ (Section 1.1).

The results obtained are shown in Table 6. 


\begin{tabular}{ccc}
\hline CASE STUDY & $\boldsymbol{R}, \mathrm{m}$ & $\boldsymbol{A}, \mathrm{m}$ \\
\hline 4 & 60 & 48.16 \\
\hline 5 & 80 & 64.89 \\
\hline 6 & 100 & 74.23 \\
\hline
\end{tabular}

Determination of the geometric and kinematic parameters is done in the same way as in the case of the hyperclothoids (Section 3.1) and the values obtained are completely equivalent (Table 8).

\subsection{Case studies 7-8-9: the Bloss curve}

Scale factor $A_{2}$ is calculated from the second expression of (22). For this purpose, it was necessary to assign an arbitrary value (for convenience it was assumed equal to the radius of the exit curve, $60 \mathrm{~m}$, $80 \mathrm{~m}, 100 \mathrm{~m}$ ) to $A_{1}$ and the length of the corresponding hyperclothoid or clothoid - to the Bloss curve length $L_{B C}$ (Table 8).

The final results are shown in Table 7.

Also, in this case, the geometrical and kinematic parameters are completely equivalent to those of the hyperclothoids and, therefore, of the clothoids (Table 8).

The planimetric scheme of the designed exit lanes (case studies 1-9) is shown in Figure 3.

Table 7. Design Bloss curve: scale factors $A_{1}$ and $A_{2}$

\begin{tabular}{cccc}
\hline CASE STUDY & $\boldsymbol{R}, \mathbf{m}$ & $\boldsymbol{A}_{\mathbf{1}}, \mathbf{m}$ & $\boldsymbol{A}_{\mathbf{2}}, \mathbf{m}$ \\
\hline 7 & 60 & 60 & 59.49 \\
\hline 8 & 80 & 80 & 79.74 \\
\hline 9 & 100 & 100 & 95.35 \\
\hline
\end{tabular}

Table 8. Summary of design data and geometric and kinematic results (case studies 1-9)

\begin{tabular}{|c|c|c|c|c|c|c|c|c|c|c|c|}
\hline $\begin{array}{c}\text { CASE } \\
\text { STUDIES }\end{array}$ & $\begin{array}{l}R, \\
\mathrm{~m}\end{array}$ & $\begin{array}{c}V_{\mathrm{ft}} \\
\mathrm{km} / \mathrm{h}\end{array}$ & $\begin{array}{c}v_{\mathrm{f}} \\
\mathrm{m} / \mathrm{s}\end{array}$ & $\begin{array}{c}V_{\mathrm{i},} \\
\mathrm{km} / \mathrm{h}\end{array}$ & $\begin{array}{c}v_{i,} \\
m / s\end{array}$ & $\begin{array}{c}a_{1} \\
\mathrm{~m} / \mathrm{s}^{2}\end{array}$ & $\begin{array}{c}V_{x \prime} \\
\mathrm{km} / \mathrm{h}\end{array}$ & $\begin{array}{l}v_{x \prime} \\
m / s\end{array}$ & $\begin{array}{c}L_{m, u r} \\
\mathbf{m}\end{array}$ & $\begin{array}{c}L_{d, u \prime} \\
\mathbf{m}\end{array}$ & $\begin{array}{l}L^{*}, \\
\mathrm{~m}\end{array}$ \\
\hline $1-4-7$ & 60 & 30 & 8.33 & \multirow{3}{*}{90} & \multirow{3}{*}{25} & \multirow{3}{*}{1.4} & 47.99 & 13.33 & \multirow{3}{*}{30} & 198.43 & 38.66 \\
\hline $2-5-8$ & 80 & 35 & 9.72 & & & & 55.98 & 15.55 & & 189.47 & 52.64 \\
\hline $3-6-9$ & 100 & 40 & 11.11 & & & & 60.01 & 16.67 & & 179.13 & 55.10 \\
\hline
\end{tabular}

Note: * transition curve length. 


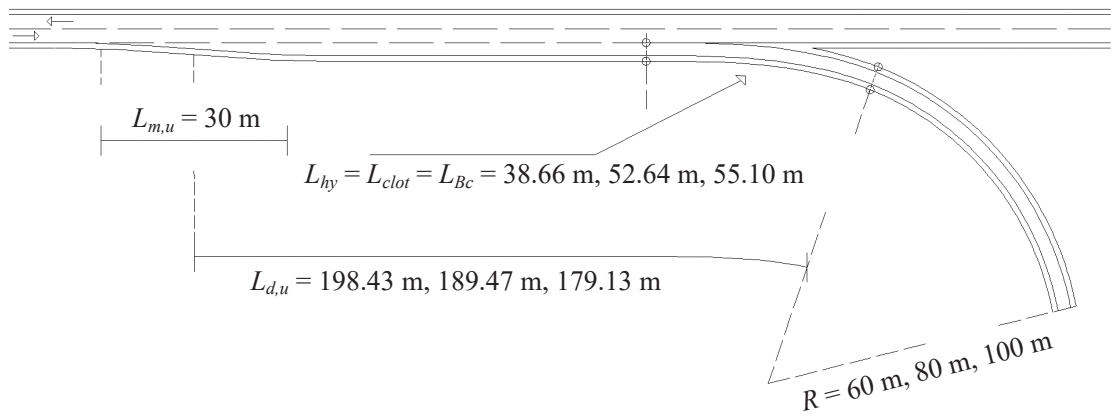

Figure 3. Planimetric scheme of the designed exit lanes (case studies 1-9)

\section{Kinematic parameters}

In order to compare the kinematic performances of the designed transition curves, four important parameters are taken into account: lateral acceleration $a_{t}$, lateral jerk $c$, steering speed $\dot{\vartheta}$ and rolling speed $\dot{u}$ of the roadway. Since we have designed transition curves of equal length (Section 3 ), the $\dot{u}$ parameter loses its significance. In any case, its evaluation is useful to verify that the recommended limits are not exceeded (Section 5). The trends of $c, a_{t}$ and $\dot{\vartheta}$ were analyzed and compared under hypothesis of uniformly varied motion, with an imposed longitudinal deceleration of $1.4 \mathrm{~m} / \mathrm{s}^{2}$.

\subsection{Hyperclothoid: analytical formulation of kinematic parameters}

The expressions for the calculation of lateral acceleration, lateral jerk and steering speed are given in Section 1.2 (Eqs. (11), (12) and (13)).

These expressions (with the exception of the one that allows the calculation of the steering speed) are valid in the absence of roadway superelevation. Anyway, the superelevation is always achieved because it helps to partially compensate the lateral acceleration and reduce the lateral jerk. If $g$ is the gravity acceleration, $m$ - the mass of the vehicle, $\theta$ - the generic roadway rotation angle, and $v$ - the instantaneous vehicle speed in $\mathrm{m} / \mathrm{s}$ (Figure 4) it is deduced that with the superelevation, $a_{t}$ is reduced by $g \cdot \tan \theta$ or by a value equal to $g \theta^{\mathrm{rad}}$. In this case, Eq. (11) takes the following form:

$$
a_{t}=\left(\frac{v^{2}}{r}-g \theta^{\mathrm{rad}}\right)=\left(\frac{v^{2}}{A^{n+1}} s^{n}-g \theta^{\mathrm{rad}}\right) .
$$




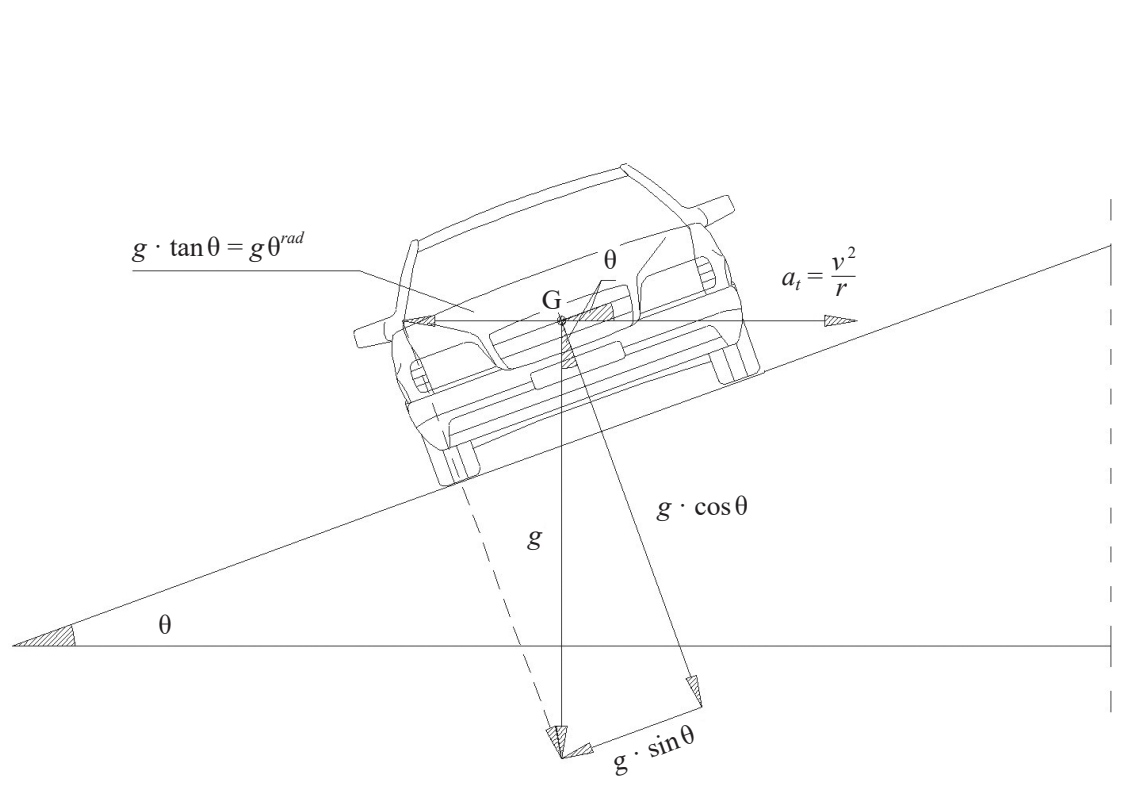

Figure 4. Cross-section of the roadway and pseudo-dynamic balance of the in-curve vehicle

At the hyperclothoid starting point $(s=0)$, the roadway rotation angle $\theta$ is equal to $0.025 \mathrm{rad}$, while at the end point $\left(s=L_{h y}\right)$ it is equal to $0.07 \mathrm{rad}$ (MIT, 2001). If $\theta$ assumes a linear trend in function of the hyperclothoid curvilinear abscissa $s$ and we impose to it the abovementioned boundary conditions, Eq. (28) assumes the following form:

$$
a_{t}=\left[\frac{v^{2}}{r}-g\left(\frac{0.045}{L_{h y}} s+0.025\right)\right]=\left[\frac{v^{2}}{A^{n+1}} s^{n}-g\left(\frac{0.045}{L_{h y}} \cdot s+0.025\right)\right] \text {. }
$$

The lateral jerk $c$ is the variation of lateral acceleration in the time unit. If we replace Eq. (29) in $c=\mathrm{d} a_{t} / \mathrm{d} t$, we consider Eqs. (11) and (12) and we attribute to $v$ the meaning of instantaneous vehicle speed in the generic point with curvilinear abscissa $s$ (Section 1.3), the analytical formulation of the lateral jerk is:

$$
c=\frac{\mathrm{d} a_{t}}{\mathrm{~d} t}=\left(v^{3} \frac{n}{A^{n+1}} s^{n-1}\right)-\left(\frac{g}{L_{h y}} 0.045 v\right) .
$$

For the rolling speed $\dot{u}$ the same procedure as for the clothoid is used (Sections 1.1-1.2 and Eq. (8)). 


\subsection{Clothoid: analytical formulation of kinematic parameters}

The same considerations as those formulated for the hyperclothoid remain true (Section 4.1). The final expressions are obtained by placing $n=1$ and $L_{h y}=L_{\text {clot }}$ in Eqs. (29) and (30):

$$
\begin{gathered}
a_{t}=\left[\frac{v^{2}}{r}-g\left(\frac{0.045}{L_{\text {clot }}} s+0.025\right)\right]=\left[\frac{v^{2}}{A^{2}} s-g\left(\frac{0.045}{L_{\text {clot }}} s+0.025\right)\right] ; \\
c=\frac{\mathrm{d} a_{t}}{\mathrm{~d} t}=\frac{v^{3}}{A^{2}}-\left(\frac{g}{L_{\text {clot }}} 0.045 v\right) .
\end{gathered}
$$

\subsection{Bloss curve: analytical formulation of kinematic parameters}

To obtain the expression of the lateral acceleration it is sufficient to subtract from the $a_{t}$ general formula (Eq. (21)) the contribution of the superelevation, represented by the second member of Eq. (29).

Indicating with $L_{B C}$ the length of the Bloss curve:

$$
a_{t}=\frac{v^{2}}{r}=\left[\frac{v^{2} s^{2}}{R L_{B c}^{2}}\left(3-\frac{2 s}{L_{B c}}\right)\right]-g\left[\left(\frac{0.045}{L_{B c}} s+0.025\right)\right] .
$$

For the lateral jerk calculation, Eq. (33) is replaced in its general expression $\left(c=\mathrm{d} a_{t} / \mathrm{d} t\right)$ and both Eq. (20) and the meaning attributed to $v$ are taken into account (Section 1.3). As in the case of hyperclothoids, it results in:

$$
c=\frac{\mathrm{d} a_{t}}{\mathrm{~d} t}=\left[v^{3} s\left(\frac{2}{A_{1}^{3}}-\frac{3 s}{A_{2}^{4}}\right)\right]-\left[\frac{g}{L_{B c}} 0.045 v\right] .
$$

\section{Limits and requirements towards kinematic parameters}

For lateral jerk $c$, the literature identifies a number of limits that should not be exceeded to ensure safe and comfortable driving conditions. For example, in the case of highways, the AASHTO considers a range of $c$ between $0.3 \mathrm{~m} / \mathrm{s}^{3}$ and $0.9 \mathrm{~m} / \mathrm{s}^{3}$ (AASHTO, 2001) acceptable. Other authors (Schofield, 2001) accept, instead, a maximum value of 
$0.6 \mathrm{~m} / \mathrm{s}^{3}$ in the residential area and $0.3 \mathrm{~m} / \mathrm{s}^{3}$ in the rural area, or $0.6 \mathrm{~m} / \mathrm{s}^{3}$ in any conditions (Uren \& Price, 2006). The following is an analytical expression that allows calculation of the maximum permissible jerk $c_{\text {max }}$ as a function of speed $v$ expressed in $\mathrm{m} / \mathrm{s}$ (or $V$ expressed in $\mathrm{km} / \mathrm{h}$ ) (MIT, 2001):

$$
c_{\max }=\frac{14}{v}=\frac{50.4}{V}
$$

Limit values are also suggested for lateral acceleration $a_{t}$, which should not be exceeded. For example, according to the German RAL Standards, the maximum value tolerated by passengers in cars is $1.47 \mathrm{~m} / \mathrm{s}^{2}$ (Kilinç \& Baybura, 2012). For highways, an indicative limit of $2.45 \mathrm{~m} / \mathrm{s}^{2}$ is recommended (Schofield, 2001).

However, for the steering speed $\dot{\vartheta}$ there are no experimental limits (Giannini et al., 1993). For this reason, the reference value is obtained by replacing the maximum lateral jerk formula (35) in the general expression of $\dot{\vartheta}$, valid for all types of curves: clothoid (7), hyperclothoid (13) and the Bloss curve (25). The following analytical expression is obtained:

$$
\dot{\vartheta}_{\max }=14 \frac{p}{v^{3}}
$$

The last kinematic parameter to be taken into account is the roadway rolling speed $\dot{u}$. The literature limit values adopted by various international standards are quite similar (Cenek et al., 2011). In particular, the maximum value of $\dot{u}$ compatible with the desired comfort level is assumed to be $0.044 \mathrm{rad} / \mathrm{s}$ (California Department of Transportation, 2006) and this limit is practically the same as the value of $0.05 \mathrm{rad} / \mathrm{s}$ adopted (MIT, 2001).

\section{Results}

The results drawn as a function of the dimensionless curvilinear abscissa are shown graphically in Figures 5 and 6. All kinematic analyses were "locally" carried out (point-by-point) along the transition curves. This means that after having subdivided their generic total length $L$ into a suitable number of elementary sections (in the specific case n.10 sections of length $\bar{l}=L / 10$ ), the speed has been calculated in each of the $\mathrm{k}$ extremities of $\bar{l}$ applying the uniformly varied motion law, with the deceleration of $1.4 \mathrm{~m} / \mathrm{s}^{2}$ :

$$
v_{k}=\sqrt{v_{k-1}^{2}-2 a \bar{l}}, \text { where } k=0,1,2, \ldots, 10 .
$$




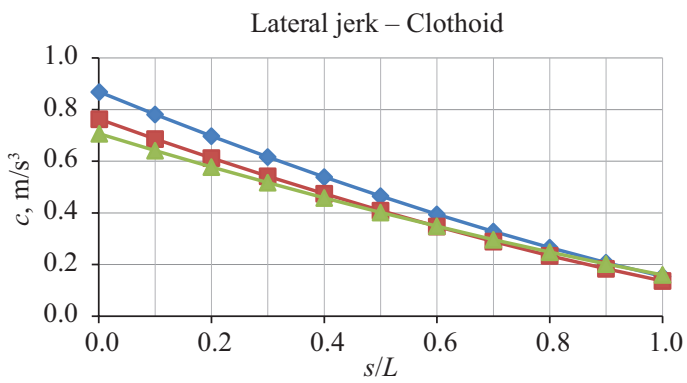

a) case studies 1-2-3

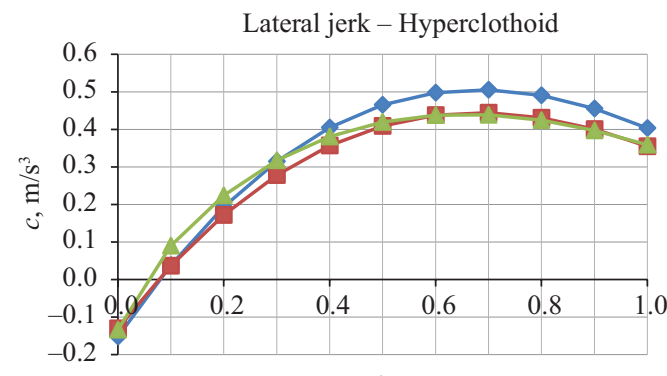

b) case studies 4-5-6

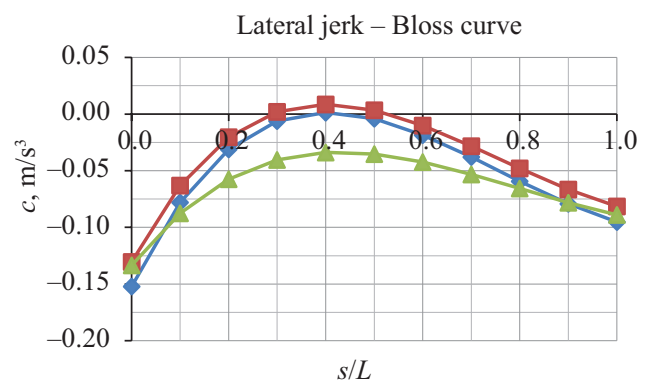

c) case studies 7-8-9

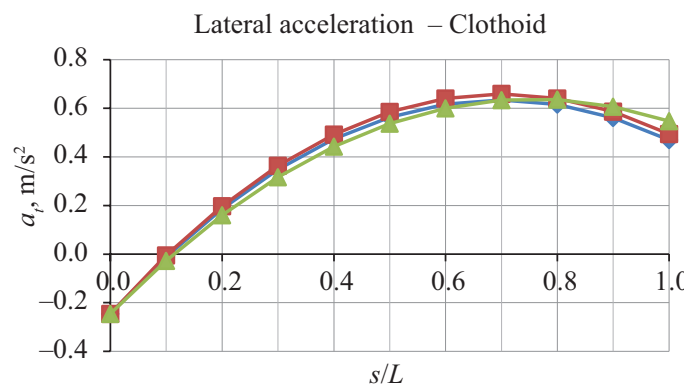

d) case studies 1-2-3

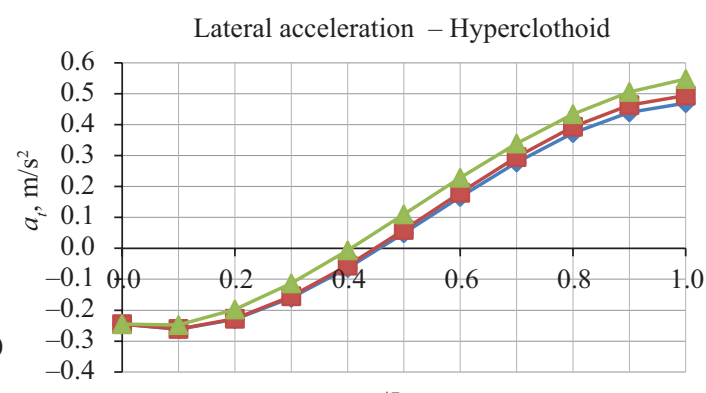

e) case studies 4-5-6

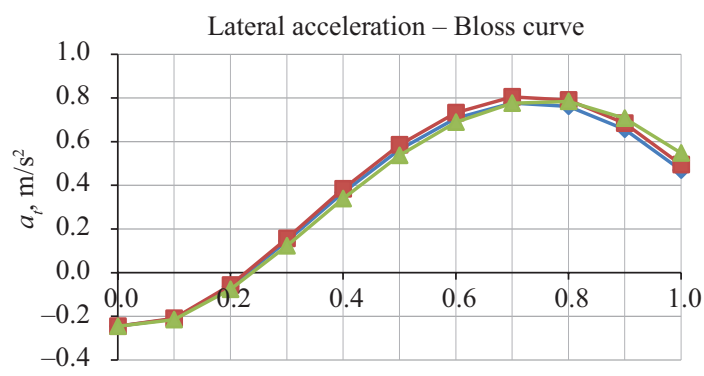

$s / L$

f) case studies 7-8-9

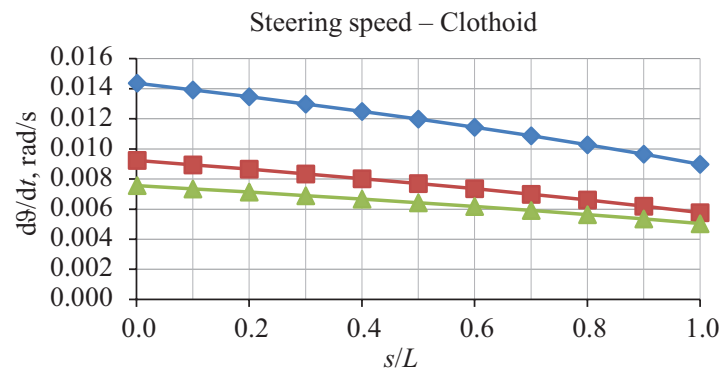

g) case studies 1-2-3

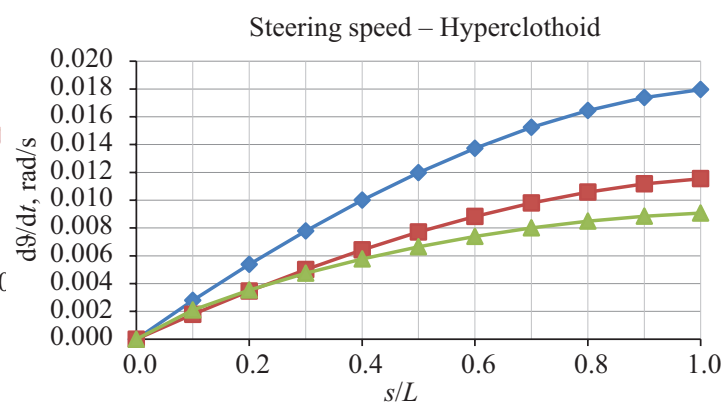

h) case studies 4-5-6 


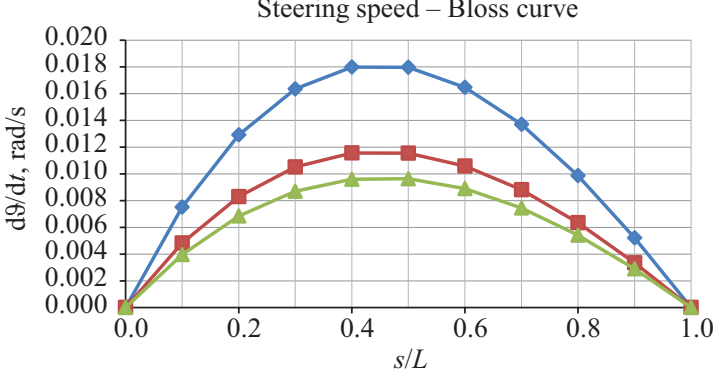

i) case studies 7-8-9

Figure 5. Kinematic comparison with the variation of the exit curve radius

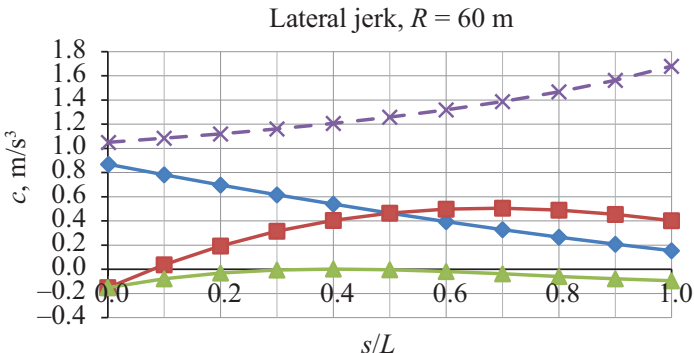

a) case studies 1-4-7

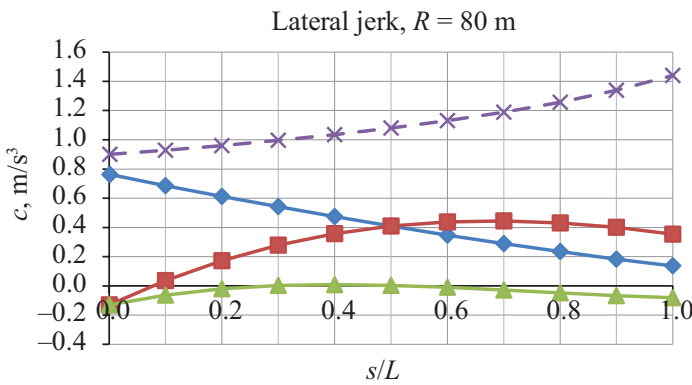

b) case studies $2-5-8$

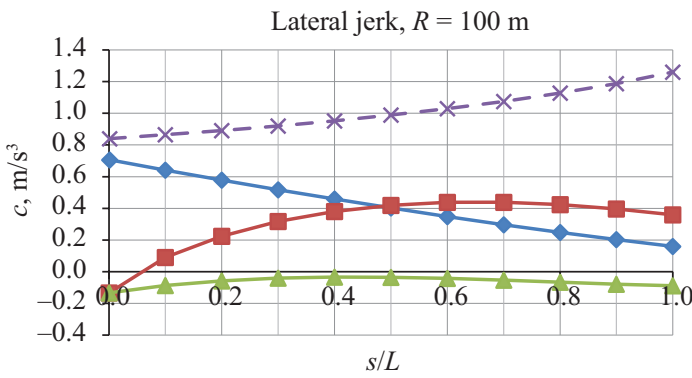

c) case studies 3-6-9
Lateral acceleration, $R=60 \mathrm{~m}$

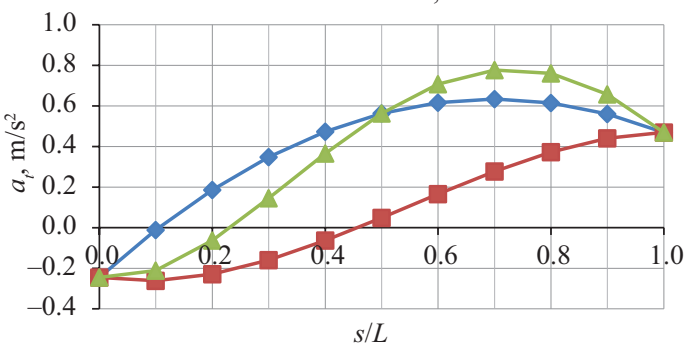

d) case studies 1-4-7

Lateral acceleration, $R=80 \mathrm{~m}$

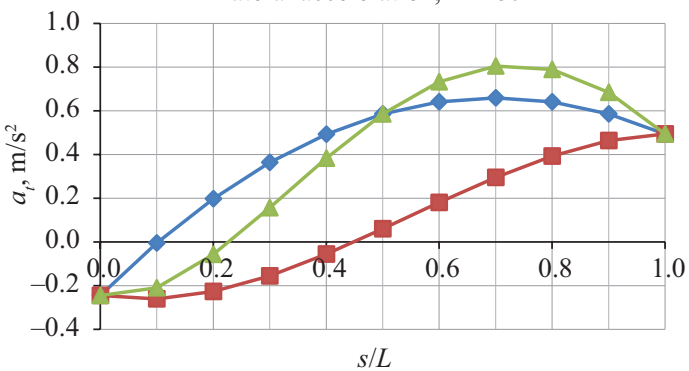

e) case studies 2-5-8

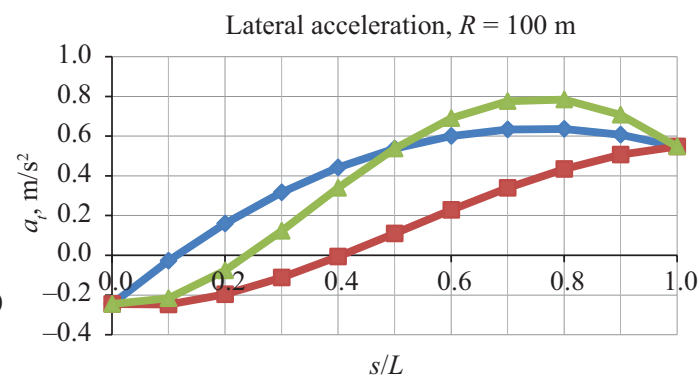

f) case studies 3-6-9 


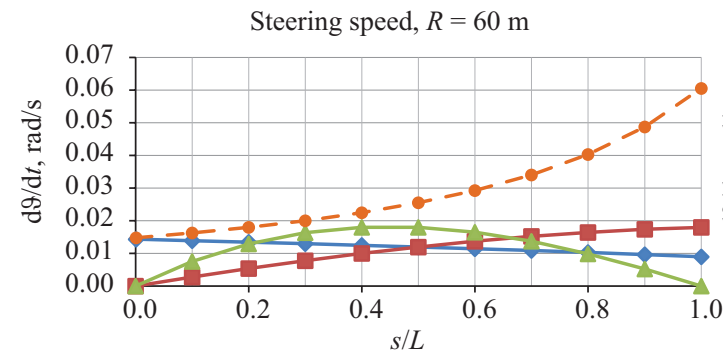

g) case studies 1-4-7

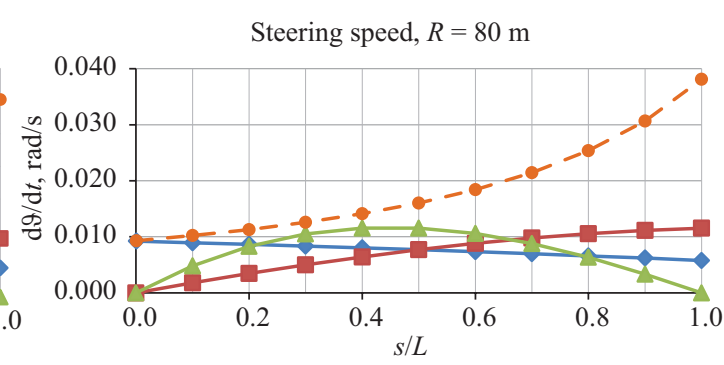

h) case studies $2-5-8$
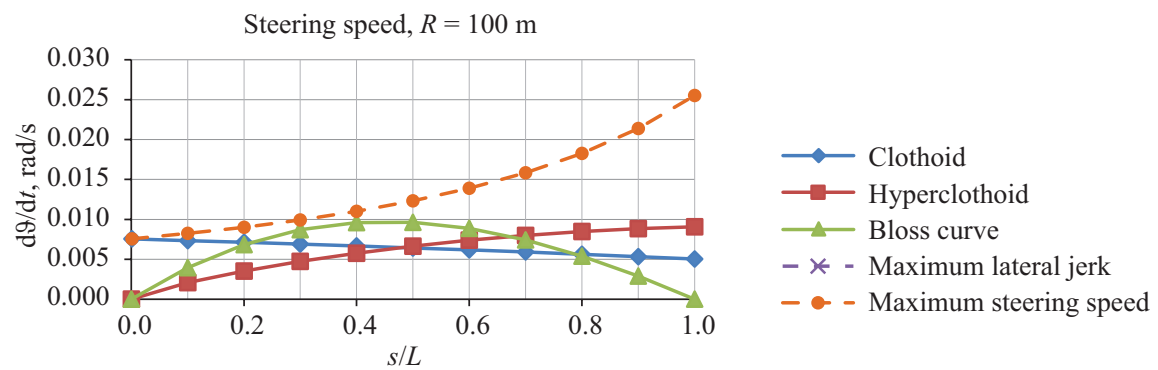

i) case studies 3-6-9

Figure 6. Kinematic checks and comparisons between different types of transition curves

Table 9. Speed along transition curves (case studies 1-9)

\begin{tabular}{|c|c|c|c|c|c|c|c|c|c|}
\hline $\begin{array}{c}\text { CASE } \\
\text { STUDIES }\end{array}$ & $s / L$ & $\begin{array}{c}V_{k \prime} \\
\mathrm{km} / \mathrm{h}\end{array}$ & $\begin{array}{c}v_{k \prime} \\
\mathrm{m} / \mathrm{s}\end{array}$ & $\begin{array}{c}\text { CASE } \\
\text { STUDIES }\end{array}$ & $\begin{array}{c}V_{k \prime} \\
\mathrm{km} / \mathrm{h}\end{array}$ & $\begin{array}{c}v_{k \prime} \\
\mathrm{m} / \mathrm{s}\end{array}$ & $\begin{array}{c}\text { CASE } \\
\text { STUDIES }\end{array}$ & $\begin{array}{c}V_{k \prime} \\
\mathrm{km} / \mathrm{h}\end{array}$ & $\begin{array}{l}v_{k \prime} \\
\mathrm{m} / \mathrm{s}\end{array}$ \\
\hline \multirow{11}{*}{$1-4-7$} & 0.0 & 47.99 & 13.33 & \multirow{11}{*}{$2-5-8$} & 55.98 & 15.55 & \multirow{11}{*}{$3-6-9$} & 59.98 & 16.66 \\
\hline & 0.1 & 46.50 & 12.92 & & 54.26 & 15.07 & & 58.30 & 16.20 \\
\hline & 0.2 & 44.96 & 12.49 & & 52.47 & 14.57 & & 56.56 & 15.71 \\
\hline & 0.3 & 43.37 & 12.05 & & 50.61 & 14.06 & & 54.77 & 15.21 \\
\hline & 0.4 & 41.73 & 11.59 & & 48.69 & 13.52 & & 52.91 & 14.70 \\
\hline & 0.5 & 40.01 & 11.11 & & 46.69 & 12.97 & & 50.98 & 14.16 \\
\hline & 0.6 & 38.22 & 10.62 & & 44.59 & 12.39 & & 48.98 & 13.61 \\
\hline & 0.7 & 36.33 & 10.09 & & 42.40 & 11.78 & & 46.90 & 13.03 \\
\hline & 0.8 & 34.35 & 9.54 & & 40.08 & 11.13 & & 44.72 & 12.42 \\
\hline & 0.9 & 32.24 & 8.96 & & 37.62 & 10.45 & & 42.42 & 11.78 \\
\hline & 1.0 & 30.00 & 8.33 & & 35.00 & 9.72 & & 40.00 & 11.11 \\
\hline
\end{tabular}


It should be noted that at the initial point of the transition curves $(k=0) v_{k}=v_{x}$ is true, while at the final point $(k=10) v_{k}$ coincides with $v_{f}$ i.e. with the design speed of the circular exit curves (Section 3.1 and Table 8).

The obtained results are summarized in Table 9.

\subsection{Lateral jerk}

Figures 5a-c show the lateral jerk trend as a function of the dimensionless curvilinear abscissa $s / L$. The $c$ value has been drawn for each type of examined curves as the radius $R$ of the exit curve varies $(R=60 \mathrm{~m}, 80 \mathrm{~m}, 100 \mathrm{~m})$. Figures $6 \mathrm{a}-\mathrm{c}$ show the lateral jerk trend (with the same radius $R$ ) for each of the three types of analyzed curves. The analysis of these diagrams shows the following:

1) the maximum jerk (in absolute values) is always lower than the limit values in the scientific literature (Section 5). In particular, for the Bloss curve, the maximum lateral jerk is significantly lower than the above-mentioned limits (Figures 6a-c);

2 ) the influence of the exit radius $R$ on the maximum lateral jerk is low for the clothoid and the hyperclothoid (variation of about $20 \%$ and about 15\%, respectively, in the passage from $R=60 \mathrm{~m}$ to $R=100 \mathrm{~m}$ (Figures $5 \mathrm{a}-\mathrm{b}$ )) and is more sensitive for the Bloss curve (variation of more than $130 \%$ in the passage from $R=80 \mathrm{~m}$ to $R=100 \mathrm{~m}$ (Figure $5 \mathrm{c}$ ));

3) for each $R$ value, the hyperclothoid shows a better behavior than the clothoid only in the first half of its length. In fact, in this section, the lateral jerk values are lower and without the starting peak. The Bloss curve shows a more regular trend, sufficiently flat and with maximum values much lower than those demonstrated by the two previous curves (Figures 6a-c).

4) the clothoid, compared to other types of curves, generates a high initial jerk that significantly worsens the safety and comfort of travel;

5) the lateral jerk maximum values evaluated by expression (35) are higher than the maximum values indicated in Section 5 and largely meet the calculation results (Figures 6a-c).

\subsection{Lateral acceleration}

The trend of lateral acceleration $a_{t}$ is shown in Figures $5 \mathrm{~d}-\mathrm{f}$ (comparison with changes in $R$ ) and Figures $6 \mathrm{~d}-\mathrm{f}$ (comparison with changes in the type of transition curve). It should be noted that: 
1) in all cases, the maximum value of lateral acceleration is largely precautionary compared to the maximum values suggested by literature (Section 5 and Figures $5 \mathrm{~d}-\mathrm{f}$ );

2) the influence of the exit radius $R$ on the maximum value of the lateral acceleration is smaller than jerk and, on average, not more than $18 \%$ (Figures $5 \mathrm{~d}-\mathrm{f}$ );

3) the hyperclothoid is most affected by the roadway superelevation. In fact, in the first part of its development (equal to about $40 \%$ of its length) it is characterized by a negative lateral acceleration, i.e. by a beneficial overcompensation (Figures $6 \mathrm{~d}-\mathrm{f}$ ). This is also the case for the other transition curves, but for a more limited length of their initial section, this is about $10 \%$ for the clothoid and $22 \%$ for the Bloss curve (Figures 6d-f). This influence is also evident in the second part of its length, considering that the $a_{t}$ value is much lower than that assessed on the clothoid and on the Bloss curve;

4) the trend of $a_{t}$ along the hyperclothoid is always increasing, except in the first section equal to $10 \%$ of the total length (Figures $6 \mathrm{~d}-\mathrm{f}$ ). This means that the $a_{t}$ maximum value falls outside the end point of the curvilinear abscissa $\xi=s / L=1$. This is certainly the best situation compared to the other situations that might have occurred, i.e. $0.8<\xi \leq 0.9$ (situation to avoid) and $0.9<\xi \leq 1.0$ (acceptable situation) (La Camera, 1992);

5) the $a_{t}$ trend of the Bloss curve is located in an approximately intermediate position between the clothoid and the hyperclothoid (Figures 6d-f). This only applies to $s / L \leq 0.3$. For $0.3<s / L \leq 0.5$, the Bloss curve $a_{t}$ values increase significantly compared to those of the hyperclothoid and tend to align with the clothoid values. For $s / L>0.5$, the Bloss curve shows $a_{t}$ values higher than those of the clothoid (about 20\%) and clearly higher than those of the hyperclothoid (about 180\%).

\subsection{Steering speed}

The results obtained are summarized in Figures 5g-i and Figures $6 \mathrm{~g}-\mathrm{i}$.

It is noted that:

1) the steering speed trend along the transition curves (Figures $5 \mathrm{~g}-\mathrm{i}$ ) have very different shapes (decreasing, increasing or bellshaped respectively for clothoid, hyperclothoid and Bloss curve);

2) the influence of the exit radius $R$ on the steering speed is relevant (Figures $5 \mathrm{~g}-\mathrm{i}$ ). Moving from $R=60 \mathrm{~m}$ to $R=100 \mathrm{~m}$ there is a maximum variation of $\dot{\vartheta}$ between 85\% (clothoid) and 100\% (hyperclothoid and Bloss curve); 
3) the steering speed limit values evaluated by expression (36) largely comply with the calculation results, especially in the second half of the curve length. Note that wheelbase $p$ of the vehicle of $2.5 \mathrm{~m}$ has been assumed, corresponding to the case of a small car. For $0.2 \leq s / L \leq 0.5$, the Bloss curve values are instead very close to the admissible maximum and this situation is repeated for the clothoid in its initial section for $s / L<0.2$ (Figures 6g-i);

4) at the clothoid starting point, the presence of an instantaneous value of $\dot{\vartheta}$ can be observed (Figure $5 \mathrm{~g}$ ) and this negatively affects both safety and driving comfort;

5) the trend of $\dot{\vartheta}$ along the Bloss curve is of bell type, i.e. increasing in the first half of its length and decreasing in the final part (Figure 5i);

6) the maximum value of $\dot{\vartheta}$ at the hyperclothoid end point (Figures $6 \mathrm{~g}-\mathrm{i})$ coincides with that of the Bloss curve approximately at its intermediate point $(s / L=0.5)$.

\subsection{Rolling speed}

The last kinematic parameter to be evaluated is the roadway rolling speed $\dot{u}$ (Section 1.1). Given that at the end and the beginning of the transition curve, the roadway (single slope) has a lateral slope of 7.0\% and 2.5\%, respectively (MIT, 2001), then the rotation angles of the same roadway (Figure 4) are equal to a $\vartheta_{f} \approx 0.07 \mathrm{rad}$ and $\vartheta_{x} \approx 0.025 \mathrm{rad}$ (Eq. (8)).

The travel time $t$ of the generic transition curve is obtained by applying the uniformly varied motion formula, that is:

$$
t=\frac{v_{f}-v_{x}}{a},
$$

where (Section 3.1 and Table 8) $v_{f}$ - speed at the end of the transition curve, $\mathrm{m} / \mathrm{s} ; v_{x}-$ speed at the beginning of the transition curve, $\mathrm{m} / \mathrm{s} ; a-$ constant deceleration set at $1.4 \mathrm{~m} / \mathrm{s}^{2}$.

The results obtained by applying Eqs. (8) and (38) are summarized in Table 10 . It should be noted that $\dot{u}$ is always below $\dot{u}_{\text {max }}$ (Section 5).

Table 10. Rolling speed of the roadway (case studies 1-9)

\begin{tabular}{ccccc}
\hline $\begin{array}{c}\text { CASE } \\
\text { STUDIES }\end{array}$ & $\begin{array}{c}\boldsymbol{R}_{\boldsymbol{\prime}} \\
\mathrm{m}\end{array}$ & $\begin{array}{c}\boldsymbol{t}_{\boldsymbol{i}} \\
\mathbf{s}\end{array}$ & $\begin{array}{c}\boldsymbol{u}_{\boldsymbol{i}} \\
\mathrm{rad} / \mathrm{s}\end{array}$ & $\begin{array}{c}\dot{\boldsymbol{u}}_{\mathbf{m a x} \mathbf{m}^{\prime}} \\
\mathrm{rad} / \mathrm{s}\end{array}$ \\
\hline $1-4-7$ & 60 & 3.57 & 0.0126 & \\
\hline $2-5-8$ & 80 & 4.16 & 0.0108 & 0.05 \\
\hline $3-6-9$ & 100 & 3.97 & 0.0113 & \\
\hline
\end{tabular}




\section{Conclusions}

The conclusions of this kinematic study, which proposes the use of the Bloss curve as an alternative braking curve, can be summarized as follows.

1. The Bloss curve shows lateral jerk values significantly lower than those exhibited by both the clothoid and the hyperclothoid along the entire length of the transition curve.

2. The Bloss curve shows values of lateral acceleration always higher than those of the hyperclothoids and higher than those of the clothoid only in the second half of its length. However, the maximum value of lateral acceleration detected on the Bloss curve, although it is always higher than that of both clothoids and hyperclothoids, is equal to about $0.8 \mathrm{~m} / \mathrm{s}^{2}$ and, therefore, is significantly lower than the limit values suggested by the scientific literature and international standards.

3. Similar considerations can be formulated for the steering speed, because the Bloss curve, for much of its development (about $65-70 \%$ ) exhibits values of $\dot{\vartheta}$ higher than those of the corresponding hyperclothoids. The calculated values are still lower than the maximum reference values.

The Bloss curve can be proposed as a braking curve in the exit lanes, since lateral jerk is recognized as a fundamental kinematic parameter in the design of transition curves, and lateral acceleration, steering speed and rolling speed are always below the maximum reference values. This proposal shall also be confirmed from the point of view of safety and visual perception of the transition element.

\section{REFERENCES}

Agostinacchio, M. (1983). La curva biparametrica quale raccordo planimetrico stradale a gradiente di curvatura progressivo. Autostrade, (3), 26-35. ISSN 00051756

Agostinacchio, M., Ciampa, D., \& Olita, S. (2010). Strade Ferrovie Aeroporti (III Edizione). Roma: EPC Libri. ISBN 978-88-6310-223-9

Agostinacchio, M., Ciampa, D., \& Olita, S. (2011). La progettazione delle strade (II Edizione). Roma: EPC Libri. ISBN 978-88-6310-326-7

AASHTO - American Association of State Highway and Transportation Officials. (2001). A policy on geometric design of highways and streets (4th ed.). Washington DC (USA). ISBN 1-56051-156-7. Retrieved from https://sjnavarro.files.wordpress.com/2011/08/aashto-2001.pdf

Blaschke, W. (1956). Kinematogrammetrische Ermittlung der Verzögerung während der Bremsung beim Ausfahren aus der Autobahn. StrV. 1/1956. 
Blaschke, W. (1958). Die Ausfahrt an anschlussstellen ein aktuelles Problem der Autobahntrassierung. FA (26).

Blaschke, W. (1959). Die bremskurve als trassierungselement, Ausbildung von Bremsstrecken von engen Strassenbögen. BrStr. 1/1959.

Bloss, A. E. (1936). Der Ubergangsbogen mit geschwungener Uberhohungsrampe. Organ fur die Fortschritte des Eisenbahnwesens, 73(15), 319-320.

California Department of Transportation. (2006). Highway Design Manual. Retrieved from https://dot.ca.gov/programs/design

Cenek, P. D., Jamieson, N. J., Henderson, R. J., \& Davies, R. B. (2011). Improved rate-of-rotation design limits. NZ Transport Agency research report 456. ISBN 978-0-478-38055-2. Retrieved from https://www.nzta.govt.nz/assets/ resources/research/reports/456/docs/456.pdf

Ciobanu, C. (2015). Bloss transition-a short design guide. PWI Journal, 133(2), 14-18. Retrieved from https://www.researchgate.net/publication/282288817 Bloss_transition_-_a_short_design_guide

Giannini, F., La Camera, F., \& Marchionna, A. (1993). Appunti di costruzione di strade ferrovie ed aeroporti per il corso di laurea in ingegneria civile trasporti (II Edizione). Masson Editoriale ESA. ISBN 88-405-3223-4

Heller, F., \& Blaschke, W. (1961). Design of interchanges of rural freeways. In Proceedings of the Giornate internazionali di tecnica della circolazione, Washington, USA.

Kilinç, A. S., \& Baybura, T. (2012). Determination of minimum horizontal curve radius used in the design of transportation structures, depending on the limit value of comfort criterion lateral jerk. In Proceedings of the FIG Working Week 2012-territory, environment, and cultural heritage, Rome, Italy. ISBN 97887-90907-98-3.

Kobryń, A. (2017). Transition curves for highway geometric design. Springer Tracts on Transportation and Traffic, vol.14. Springer International Publishing. ISBN: 978-3-319-53726-9. https://doi.org/10.1007/978-3-319-53727-6

Kufver, B. (1997). Mathematical description of railway alignments and some preliminary comparative studies. Swedish National Road and Transport Research Institute, VTI Rapport 420A. ISSN: 0347-6030. Retrieved from http://www.diva-portal.se/smash/get/diva2:675179/FULLTEXT01.pdf

La Camera, F. M. (1992). Il calcolo del progetto stradale-La planimetria (II Edizione). Masson Editoriale ESA. ISBN 88-405-3234-x

Lorenz, H. (1971). Trassierung und Gestaltung von Strassen und Autobahnen, cap. I. Geometrie der Linienfuhrung, Bauverlag GMBH Wiesbaden und Berlin.

MIT - Ministero delle Infrastrutture e dei Trasporti. (2001). Norme funzionali e geometriche per la costruzione delle strade. D.M. 05-11-2001, G.U. Serie Generale n.3 (04-01-2002), S.0. n.5. Retrieved from http://www.mit.gov.it/mit/site.php?p=normativa\&o=vd\&id=216

MIT - Ministero delle Infrastrutture e dei Trasporti. (2006). Norme funzionali e geometriche per la costruzione delle intersezioni stradali, D.M. 19-04-2006, G.U. n.170 (24-07-2006). Retrieved from

http://www.mit.gov.it/mit/site.php?p=normativa\&o=vd\&id=1735\&id cat $=$ \&id_dett $=0$ 
Nemesdy, E. (1984). Geometrie und berechnung von hyperklothoiden mit zwei parametern für strassenprojektierung. Periodica Polytechnica Electrical Engineering (Archives), 29(2-4), 211-235.

Retrieved from https://pp.bme.hu/ee/article/view/4677/3782

Schofield, W. (2001). Engineering surveying: theory and examination problems for students (5th ed.). Oxford, New Delhi: Butterworth-Heinemann. ISBN 0750649879.

Taşçi, L., \& Kuloğ, N. (2011). Investigation of a New Transition Curve. The Baltic Journal of Road and Bridge Engineering, 6(1), 23-29.

Uren, J., \& Price, W. F. (2006). Surveying for Engineers (4th ed.). New York, USA: Palgrave Macmillan. ISBN 9781403920546

Wladyslaw, K. (2014). Analytical method of modelling the geometric system of communication route. Mathematical problems in engineering, 2014, 1-13. http://dx.doi.org/10.1155/2014/679817

Wladyslaw, K. (2015). Identification of transition curves in vehicular roads and railways. Logistics and Transport, 28, 31-42.

Wu, Z., Liu, Y., \& Pan, G. (2009). A smart car control model for brake comfort based on car following. IEEE Transactions on Intelligent Transportation Systems, 10(1), 42-46. https://doi.org/10.1109/TITS.2008.2006777

Zhou, J., Fang, J., \& Zhou, R.-G. (2013). Study on the safety length of acceleration and deceleration lane of left-side ramp on freeway. In Proceedings of 16th Road safety on four continents conference. China, Beijing, 15-17 May 2013. Retrieved from http://vti.diva-portal.org/smash/get/diva2:758533/FULLTEXT01 